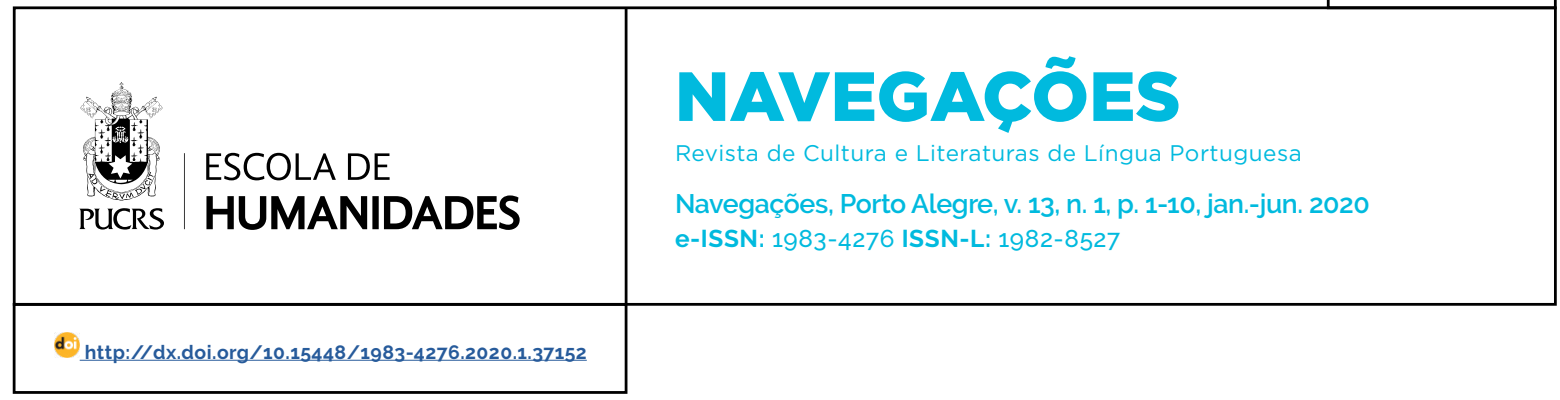

SEÇÃO: DOSSIÊ

\title{
Maksuna Brasileira: figurações do imigrante árabe nas narrativas de Salim Miguel
}

\author{
Brazilian Maksuna: the arabic immigrant's figuration in Salim Miguel's narratives
}

\section{Ana Cláudia de Oliveira da Silva ${ }^{1}$ \\ orcid.org/0000-0002-8150-6956 clauoli13@gmail.com}

Recebido em: 6 mar. 2020 Aprovado em: 8 abr. 2020. Publicado em: 10 ago. 2020
Resumo: Embora a imigração de povos de ascendência árabe para o Brasil remonte a 1884, é possivel identificar a "aparição fantasmagórica" dessa figura em nossa literatura ainda no periodo colonial. Posteriormente, na medida em que se consolida o projeto nacional romântico, a figuração do árabe modifica-se em nossas letras, percorrendo o tortuoso caminho da "exotização" à sua assimilação. Até o momento em que ocorre a inserção no cenário literário nacional de descendentes de imigrantes sírios e libaneses, redefinindo e problematizando a imagem univoca e distante pintada anteriormente. A fim de refletir acerca desse complexo processo, selecionamos alguns momentos importantes da dinâmica de figuração do árabe na literatura brasileira, conferindo especial atenção à representação do imigrante árabe nas narrativas de Salim Miguel. Esse escritor não apenas dialoga com as formas de figuração do sujeito árabe ao longo da tradição literária brasileira, como também problematiza a própria ideia de uma memória única, homogeneizadora e sem fraturas em torno da qual se organiza a identidade nacional.

Palavras-chave: Salim Miguel. Imigrante árabe. Figuração/ Personagem.

Abstract: Although the Arab-origin communities' immigration to Brazil dates back to 1884, it is possible to recognize the "ghostly apparition" of that figure in our literature, even in the colonial period. Later, as the national romantic project is strengthened, the figuration of the Arabic changes in our lyrics, following the tortuous path from its "exoticization" to its conformity. Until the moment when the descendants of Syrian and Lebanese immigrants entered the national literary scene, redefining and problematizing the univocal and distant image previously painted. To reflect on that complex process, we have selected some important moments in the dynamics of figuring the Arabic in Brazilian literature, paying special attention to the Arab immigrant's representation in Salim Miguel's narratives. That writer not only dialogues with the Arab subject symbolism patterns throughout the Brazilian literary tradition, as well as also challenges the very idea of a unique, homogenizing. and fracture-free memory around which national identity is organized. Keywords: Salim Miguel. Arab immigrant. Figuration/ Character.

\section{Introdução}

A acreditar-se nos historiadores ibéricos, sejam espanhóis sejam portugueses, a descoberta das Américas pelos turcos, que não são turcos coisissima nenhuma, são árabes de boa cepa, deu-se com grande atraso, em época relativamente recente, no século passado, não antes (AMADO, 1994, p. 1-2).

Dessa maneira principia a narrativa de Jorge Amado, A descoberta da América pelos turcos, encomendada por uma estatal italiana em comemoração aos 500 anos da conquista do continente americano pelos 
povos ibéricos. Esse início problematiza de variadas formas o relato oficial acerca do descobrimento e da identidade cultural brasileira, e, ironicamente, deixa entender que a história contada tanto por espanhóis quanto por portugueses não passa de uma "mentira bem contada".

Suspeição do discurso oficial realizada desde o título da narrativa, o qual, ao relacionar o descobrimento do continente aos povos de origem árabe, ${ }^{2}$ contesta tanto a suposta precedência dos ibéricos quanto sua pureza étnica. Dúvida reiterada, posteriormente, pela voz do narrador do "romancinho" ao polemizar acerca da presença, na esquadra de Cristóvão Colombo, de um tripulante chamado Alonso Bichara: "mouro por Bichara, espanhol por Alonso" (AMADO, 1994, p. 6).

Verdade ou intrujice, pouco importa, uma vez que a história das navegações portuguesas e espanholas nos séculos XV e XVI está intimamente relacionada aos conhecimentos difundidos pala civilização árabe-islâmica em sua travessia para o continente europeu no período de 710 a 1492. Conforme assinala Benjamin Abdala Junior:

Os primeiros colonizadores da América Latina vieram da região que os árabes chamaram de Al-Ândalus. Algarve provém de Al-Gharb al-Ândalus (Andaluzia Ocidental), que abrangia o atual Algarve e o baixo Alentejo. A maior parte da população popular de Lisboa, na época dos Descobrimentos, some-se a essas constatações, era de origem moura. Eram regiões culturalmente hibridas, para onde confluiram muitas culturas da bacia cultural mediterrânea (2012, p. 49).

Tal configuração híbrida, obviamente, não desapareceu com a reconquista do território pelos reis católicos e a expulsão dos árabes do seu último reduto (Granada), uma vez que muitos moçárabes (cristãos espanhóis que dominavam a lingua moura) permaneceram no território e continuaram a repassar os conhecimentos adquiridos e a traduzir textos em árabe para o espanhol e o português. Nessa perspectiva, tornase impossivel refletir acerca das figurações ${ }^{3}$ do árabe na literatura brasileira sem antes relacionálas ao conflitivo processo histórico-cultural vivido na Península Ibérica na época do "descobrimento" do Novo Mundo, as quais, consequentemente, herdamos enquanto colônia.

Sendo assim, ainda que a imigração de povos de ascendência árabe (sírios e libaneses principalmente) para o Brasil remonte a 1884 mesmo período em que desembarcaram grandes contingentes populacionais de origem europeia no País -, é razoável identificar a "aparição" desse outro em nossa literatura com alguns séculos de antecedência. Tal presença decorre da preocupação constante dos dirigentes católicos com a influência árabe-islâmica na Europa e corresponde, portanto, a um movimento de rechaço em relação a esse sujeito durante o periodo colonial. Posteriormente, na medida em que se consolida o projeto nacional romântico, a figuração do árabe modifica-se em nossas letras, percorrendo o tortuoso caminho da "exotização" até a sua assimilação. No entanto, será necessária a inserção no cenário literário nacional de seus descendentes para que essa imagem univoca e distante do árabe, pintada pelos românticos, seja problematizada e redefinida.

A fim de refletir acerca desse complexo processo, selecionamos alguns momentos importantes da dinâmica, conferindo especial atenção à representação do imigrante árabe nas narrativas do escritor líbano-catarinense Salim Miguel. Partimos, nesse sentido, da compreensão de que esses diferentes contextos históricos e locus de enunciação influenciaram na configuração estética do personagem árabe na literatura brasileira, uma vez que nossa cultura se encontra marcada pela convergência de sistemas socioculturais diversos e por um processo histórico desigual (CORNEJO POLAR, 1982).

\footnotetext{
2 O termo "árabe" é utilizado com o objetivo de indicar uma diversidade de povos com variadas formas de organização social e modos de vida que compartilham de uma mesma geografia. De acordo com Edward Said (2007), a palavra "árabe" remete a um agrupamento cultural e linguistico antes do que a uma religião, significando todos os povos do mundo árabe, que vão desde o Oriente Próximo ao Norte da África, do Oriente Médio até as populações que migraram para outros países.

3 O conceito de figuração fundamenta-se nas considerações de Carlos Reis (2016), segundo o qual a personagem não é um conceito estático alicerçada em um conjunto descritivo de atributos, mas uma entidade potencialmente dinâmica, uma vez que é capaz de extrapolar os limites da narrativa e modificar-se em diferentes tempos culturais.
} 


\section{Da presença fantasmagórica à} assimilação das diferenças

A "aparição" do árabe em nossa literatura remonta às primeiras manifestações escritas acerca do "achamento" da nova terra. Nessa perspectiva, se retornarmos ao texto considerado como a certidão de nascimento do Brasil e, por extensão, da nossa Literatura - a Carta de Pero Vaz de Caminha -, é possivel verificar na apreensão do escrivão em comprovar a presença e/ou ausência de traços semitas nos corpos indigenas certa construção imagética negativa desse ser ausente:

\begin{abstract}
A feição deles é parda, algo avermelhada; de bons rostos e bons narizes. Em geral são bem-feitos. Andam nus, sem cobertura alguma. [...] Os cabelos deles são corredios. E andavam tosquiados, de tosquia alta [...].

Então deitaram-se na alcatifa, para dormir, sem nenhuma preocupação de cobrirem suas vergonhas, as quais não eram circuncisadas
\end{abstract}

Nenhum deles era circunciso, mas, ao contrário, todos eram assim como nós (CAMINHA apud CASTRO, 2014, p. 90; 92; 95, grifo nosso).

Assim, embora a tez indigena seja parda, semelhante à cor morena dos árabes habitantes do Norte da África; eles possuíam "bons corpos", "bons rostos" e "bons narizes", 4 bem como não apresentavam sinais de terem sido fanados. Logo, a presença árabe em terras brasileiras povoa, enquanto possibilidade, o imaginário dos tripulantes, figurando como uma espécie de fantasma para os portugueses (VILLAR, 2012). Afirmação corroborada pela crítica de Edward Said, para quem o Oriente é uma das mais profundas e recorrentes imagens da alteridade Ocidental, seu oposto cultural. Sendo, por conseguinte, "uma parte integrante da civilização e da cultura material europeia" (SAID, 2007, p. 28, grifo do autor).

Essa presença fantasmagórica pode ser verificada também nos escritos dos primeiros colonialistas e em produções barrocas brasileiras, seja de forma associada à imagem do indígena resistente ao processo de colonização seja como prolongamento do sentimento rancoroso que havia animado os lusitanos durante séculos, principalmente depois da batalha de Alcácer-Quibir. ${ }^{5}$ Basta lembrar que a conquista da América em muitos pontos assemelha-se a uma nova Guerra Santa.

Um segundo momento desse processo de apropriação da figura do árabe na nossa literatura inicia-se na medida em que se consolida o projeto nacional romântico e os escritores e poetas brasileiros buscam afastar-se da sua equivalente portuguesa, conferindo privilégio à "cor local" e substituindo os simbolos europeus por outros, muitas vezes de feição oriental. O oriente ganha, nesse período, cores exóticas e pitorescas, próximas do olhar eurocêntrico francês em que nossos escritores se inspiravam, como também próximas do olhar lançado ao indígena. Castro Alves talvez seja uma das únicas exceções a essa perspectiva, pois suas constantes referências ao mundo oriental e à imagem do "árabe errante" partem de uma situação concreta, a escravidão.

É justamente nesse periodo - momento conturbado da vida política e sociocultural do País, cujos debates giravam em torno da causa republicana e abolicionista -, que aportam os primeiros grupos de imigrantes em terras brasileiras. Esses grupos, em sua maioria, subsidiados por grandes senhores de terra ou pelo Governo para atuarem em substituição à mão de obra escrava, fizeram parte de uma política de "branqueamento" (eugenia) da população brasileira, fundamentada nas principais teorias científicas do século XIX.

Todavia, ao contrário dos alemães, italianos e poloneses, os imigrantes de ascendência árabe não participaram dessa política. Eles vieram em pequenos grupos e de forma gradual, incentivados por pressões demográficas e econômicas, bem como pelo relato de outros compatrícios bemsucedidos que conseguiram "fazer a América". Nesse sentido, muitas são as diferenças entre esse grupo migrante e os demais que vieram para

\footnotetext{
Importa lembrar que dentre os traços físicos que caracterizam o árabe destacam-se o nariz adunco e os olhos e cabelos escuros. A tese de Valter Luciano Villar (2012), intitulada Os árabes e nós: a presença árabe na Literatura Brasileira, apresenta um estudo detalhado sobre o assunto.
} 
o Brasil, dentre as quais se destacam: os objetivos (acumular capital e retornar - caráter temporário); as circunstâncias da viagem (realizada em etapas e paga com recursos próprios ou com auxílio de parentes já instalados na nova terra); o grupo majoritário (homens jovens e solteiros, em busca de trabalho); e o padrão de ocupação do território (em decorrência da mascateação e do estabelecimento de pequenos comércios, o imigrante árabe instalou-se preferencialmente na zona urbana e ocupou uma vasta extensão territorial) (TRUZZI, 2001). Essas diferenças caracterizam esses sujeitos e ensejam a construção de imagens e estereótipos sobre eles, incidindo na forma como foram representados na literatura brasileira pós-romântica.

Desse modo, embora os imigrantes tenham adentrado na sociedade brasileira em um patamar mais elevado do que aquele relegado aos exescravos ou aos trabalhadores nativos, os sírios e libaneses, para serem aceitos, tiveram que se adequar rapidamente ao nosso modus operandi no que tange à estratificação étnico-racial. Sobre esse aspecto esclarece Truzzi:

[...] logo aprenderam a se distanciar de tudo o que cultural ou socialmente pudesse associá-los a não brancos. Isso significou manter distância não apenas de negros, mas também de muçulmanos e de todos os estereótipos a eles vulgarmente atribuidos, tais como fanatismo, poligamia, costumes exóticos etc. Conscientemente, trataram de reforçar suas imagens e de se apresentar como ocidentais, cristãos, trabalhadores e pioneiros que disseminaram o progresso ao longo de todo o território nacional (2001, p. 122).

Assimilação que, segundo Villar (2012), desagradará a Machado de Assis, o qual percebia nesse processo a expansão de uma política de alinhamento ocidental. Acerca dessa questão, importa destacar uma das crônicas do escritor, publicada no periódico Ilustração Brasileira, em fevereiro de 1878, e relacionada aos conflitos na região dos Balcãs (Guerra Turco-Russa - 1877 a 1878), ocorridos em decorrência do desmembramento do Império Otomano após a Guerra da Criméia:
Caiu enfim a Turquia, foi vencida pelo urso do norte, fato que parece alegrar a meio mundo, ainda não sei por quê.

- Por quê? Porque são infiéis - dizia-me há dias um vizinho que não põe os pés na igreja.

Qualquer que seja a culpa, a verdade é que vamos ter a paz de Europa; e parece que dentro de pouco tempo os turcos estarão na Ásia (ASSIS, 1957, p. 313).

Nesse fragmento, podemos perceber de forma clara a crítica mordaz que Machado direciona para a hipocrisia humana: quer seja em relação ao vizinho que justifica a expulsão dos turcos do continente europeu com argumentos religiosos; quer seja em relação à expressão ("Paz na Europa"), utilizada por alguns dirigentes para justificar a expansão territorial de seus países. Ademais, o "bruxo do Cosme Velho" salienta em sua crônica as consequências advindas do processo de reestruturação da produção (liberalismo econômico), principalmente o desaparecimento de tudo o que ele acreditava ser diferente dos modelos culturais propostos pelo Ocidente.

Imerso nesse círculo vicioso, o Brasil adota sem questionar a mesma visão de mundo expressa pelos países ocidentais situados acima da linha do Equador. Assim como, comemora a expansão do seu modo de vida, sem, no entanto, questionar as implicações desse processo no cotidiano de um grande contingente populacional diretamente afetado pela imposição ideológico-cultural europeia e, atualmente, americana.

Da mesma forma, abarcamos sob o signo enganoso da "democracia étnico-racial" brasileira uma gama de pessoas (migrantes ou nativos) com nacionalidades, histórias, culturas, línguas diferentes, sem realmente atentar para as dificuldades de aceitação e/ou adaptação enfrentadas por elas. Assim, nossa sociedade e, consequentemente, também nossa literatura, por meio de um processo complexo de assimilação das diferenças, irá incorporar paulatinamente o estrangeiro em seu meio, sem, no entanto, reconhecê-lo enquanto sujeito capaz de produzir diferentes significados sobre a sua própria experiência.

É o que acontece com a representação do imigrante de ascendência árabe em nossas letras 
até o momento em que começam a despontar no cenário nacional escritores que descendem dessa etnia. Dessa forma, podemos dizer que, durante grande parte do século XX, a constituição desse personagem na literatura brasileira não se afastou muito daquela imagem exótica e distante pintada pelos românticos.

\section{2 "É turco"}

Visto geralmente como esse "outro", o imigrante sírio-libanês que chegasse ao Brasil logo era rotulado de "turco", em decorrência do passaporte emitido pelo Império Turco-Otomano, que há anos dominava o território da Grande Síria. Estereótipo que encobria, por trás da aparente neutralidade documental, o estigma da repressão imposta por outra nação. Marcação da diferença que faz parte das reflexões do filho mais velho de Yussef Miguel na ficção "É turco", presente nos livros Onze de Biguaçu, mais um e Reinvenção da infância, ${ }^{6}$ do escritor Salim Miguel. Nessa história, o narrador relata a dificil adaptação no ambiente escolar do personagem, filho de imigrantes libaneses e recém-chegado à pequena cidade de Biguaçu/ SC, localizada em uma zona de colonização alemã.

Depois de alguns meses a professora chama a atenção da classe e:

Diz apontando para ele: olhem só, olhem e se mirem no exemplo, há pouco não sabia uma só letra, não conhecia uma única palavra do português, mal falava um precário português misturado com árabe e alemão, é turco, e já sabe ler e escrever melhor do que quase todos, ou todos, aqui dentro (MIGUEL, 1997. p. 17; MIGUEL, 2011, p. 20, grifo nosso).

Todavia, o elogio inesperado, ao invés de proporcionar prazer, causa no personagem um choro desenfreado:

E o filho do seu Zé, do Zé Turco, do Zé Gringo, do seu Zé da venda, raramente seu Zè Miguel, nunca seu José, desaba num choro ferrado, interminável, incontrolável, fundos soluços, lágrimas escorrendo, o que causa risos nos colegas e espanto da professora (MIGUEL, 1997 p. 17: MIGUEL, 2011, p. 20).

Choro inexplicável, o qual ele não consegue decifrar por mais que se esforce. Talvez o designativo turco: "a familia era libanesa; querer irritar o pai (mais que a mãe), era chamá-lo de turco. A Turquia (Império Otomano), durante dezenas de anos, havia dominado toda uma região que incluia Síria e Libano" (MIGUEL, 1997. p. 17; MIGUEL, 2011, p. 20).

Em nosso entendimento, a explicação para o choro desenfreado talvez esteja no símbolo da falta, pois se para o pai a identidade libanesa ainda estava bastante latente, para o filho essa questão é mais complexa, pois: descende de uma cultura, da qual pouco conhece; reside em localidades do sul do Brasil, cuja predominância é de imigrantes alemães, com os quais procura identificar-se sem sucesso; tem que aprender outra cultura, costumes e língua do país onde reside, mas é visto quase sempre com curiosidade, como um ser estranho, muitas vezes exótico. Em outras palavras, para o filho do Seo Zé Miguel a sua identidade permanece fragmentada e em constante devir, enquanto para a professora e os demais colegas ele é essencialmente o outro, um ser diferente e, nessa linha interpretativa, cultural e intelectualmente inferior aos demais. O elogio, nesse caso, apenas reforça o distanciamento, de caráter eurocêntrico/ocidental, e aponta para a rejeição daquele que não é igual a mim.

Além desse uso, a expressão "é turco" também era comumente utilizada para identificar pejorativamente os imigrantes árabes ao comércio ambulante de porta em porta e à prática da usura. Demarcação da diferença que, mesmo não causando grandes problemas de aceitação social, tampouco facilitou a vida desses sujeitos, considerados como comerciantes sovinas, mestres na arte de pechinchar e obcecados pelo lucro. Essa imagem pode ser vislumbrada em algumas produções literárias brasileiras,

\footnotetext{
6 Ambas as narrativas apresentam uma série de capitulos, relatos e personagens que se repetem ou transitam de uma para outra. Em razão dessa relação de identidade e/ou repetição entre os livros, quando citados a referência é dupla. Sobre esse aspecto da produção literária de Salim Miguel consultar o artigo A reescrita obsessiva da infância em dois livros de Salim Miguel: a criação de um espaço autoficcional, disponivel em: https://doi.org/10.12957/soletras.2019.39151.
} 
como, por exemplo, nos "mascates" de Carlos Drummond de Andrade e no personagem de Salim Abara, do romance Marco Zero - A revolução melancólica, de Oswald de Andrade:

Por todo o interior em caminhos assim, mascateara com uma lata pesada nos ombros, uma matraca na mão. Parava nas fazendas e nas povoações. Era o primeiro comércio. Vinha cobrar na volta das viagens. Chamavam-no de turco. Inútil ele dizer: - Minha rolojão é armênio.

Ninguém sabia o que isso significava. A religião do Brasil era uma festa de procissões, altares vistosos e novenas. Ele viera de um sentimento tribal semítico, onde uma série de máximas constituía a moral. Com isso trazia a bestialidade milenária do negócio (1978, p. 9, grifo nosso).

Rótulo generalizante que oculta, sob o véu da aptidão inata, as dificuldades econômicas e de adaptação enfrentadas por esses imigrantes, premidos pela necessidade de sobrevivência e, por isso, dispostos a se embrenhar no interior do País e andar longas distâncias em um território desconhecido para vender pequenas quinquilharias e itens de última necessidade. Construção imagética problematizada em Nur na escuridão. Nesse romance de Salim Miguel, o personagem do velho imigrante libanês Yussef Miguel ao ouvir a palavra mascate recua no tempo até Magé/RJ, local em que ele iniciou no comércio de porta em porta, não sem antes esclarecer:

[...] pouco importa o que uma pessoa tenha sido ou queira ser, pouco importam sonhos, desejos, aspirações, fantasias. Ao chegar ao Brasil, libaneses e sírios, árabes em geral, começam mascateando, trouxas ao ombro, sorri e acrescenta, só bem mais tarde irão tomar conhecimento do outro significado da palavra trouxa. Se estão se dando bem e o mascatear dá certo, vão deixar de ser trouxas, não demora adquirem um cavalo, uma carrocinha, depois podem ter uma vendola, um armazém, loja de tecidos, quem sabe uma fabriqueta; bem poucos enriquecem, mas as novas gerações acabam por esquecer os sacrificios dos pais, dos que não tiveram nasib [berço], some a vez dos perdedores, dos tarragada que não deram certo, dos fakir, os pobres, e o que fica, para os que estão querendo aventurar, é a fama dos raros que fizeram fortuna na boa terra, animando outros para que se aventurem, pois se a derrota se mantinha esquiva, a vitória era trombeteada (MIGUEL, 2004, p. 82).

Nesse sentido, como bem explana o personagem, a prática da mascateação em um país em que o comércio ainda era incipiente foi quiçá a única solução encontrada para obter algum retorno financeiro. Contudo, o fato de alguns terem conseguido progredir, mandando dinheiro para a familia na terra de origem ou expandindo os negócios no Brasil, não significa que essa tenha sido a realidade de todos. Se a vitória era amplamente alardeada e comemorada, a história daqueles que não obtiveram sucesso, logo era esquecida.

Colada a essa representação do comerciante inato insere-se outra, a do desbravador do ainda inóspito e desconhecido interior do Brasil. Perspectiva assumida, por exemplo, em alguns romances de Jorge Amado, em especial em A descoberta da América pelos turcos. Nesse "romancinho", o narrador constrói de forma atrelada à figura de Jamil Bichara, personagem proveniente das montanhas da Síria e do Libano, uma imagem do imigrante conquistador, pois quando aportaram no Brasil "as terras [...], onde se estabeleceram a pelejar, eram naquele então cobertas de mata virgem, apenas se iniciava o plantio de roças, a construção de casas" (AMADO, 1994, p. 8).

Ao descrevê-los, portanto, como indivíduos que contribuíram para o desenvolvimento do País, Jorge Amado demonstra uma ótica amigável em relação à integração dos imigrantes síriolibaneses na nossa sociedade, os quais ao desembarcarem aqui, nas palavras do escritor, "se fizeram brasileiros dos melhores" (1994, p. XVIII). Assimilação que revela bem o processo de homogeneização das culturas sob o signo da "democracia étnico-racial" brasileira, contribuindo para forjar uma imagem una e harmoniosa de nação à maneira de Gilberto Freyre (1998): o Brasil como um local de encontro de raças e credos.

Desse modo, nossa sociedade e, 
consequentemente, também nossa literatura, por meio de um processo complexo de assimilação das diferenças, irá incorporar paulatinamente o imigrante árabe em seu meio, sem, no entanto, dar-lhe voz ou atentar para as dificuldades de aceitação, adaptação e negociação identitária enfrentadas continuamente. Com base nisso, podemos dizer que, durante grande parte do século $X X$, a figuração desse estrangeiro na literatura brasileira não se afastou muito daquela primeira imagem negativa pintada pelos colonialistas e reescrita pelos românticos em uma perspectiva exótica e distante. Essa representação começa a ser problematizada com a inserção no cenário nacional de escritores que descendem dessa etnia ou buscam retratá-la desde uma perspectiva intima, como é o caso de Ana Miranda (1997), em Amrik.

Mudança conceptual importante e que aponta para uma transformação de âmbito mais profundo em nossas letras, a saber, a necessidade não apenas desse sujeito ver-se representado na literatura brasileira, como a possibilidade de ele contar sua história e expressar, assim, uma visão particular de mundo. "Testemunho literariamente qualificado [dessa] experiência de duplicidade" (1999, p. 68, grifo do autor), como destaca o crítico José Paulo Paes, que fará com que desponte aqui uma constelação de escritores "anfibios" (criados dentro de duas linguas-culturas diversas), como Jorge Medauer, Raduan Nassar, Waly Salomão, Milton Hatoum, Jorge Tufik, Alberto Mussa, Alcy Cheuiche, Carlos Nejar, Georges Bourdoukan, Salim Miguel.

Esses escritores, por meio de distintos gêneros textuais, procedimentos estilísticos e enfoques temáticos, colocam em "xeque" conceitos generalistas e homogêneos acerca do papel que cabe ao imigrante árabe na literatura e na sociedade brasileira. Nessa perspectiva, no lugar do turco mesquinho, dono de um comércio qualquer na esquina, com costumes exóticos e libidinosos, os emigrados ou seus filhos/netos abordam em seus textos um Oriente outro, permeado pelos labirintos da memória e por dramas familiares. Eles subvertem, dessa forma, a representação estereotipada e orientalista presente nas figurações do personagem árabe ao enfatizarem em suas narrativas o aspecto humano proveniente desse encontro conflitivo de culturas e línguas.

Isso é bastante perceptivel nas narrativas de Salim Miguel, ainda que a imigração não seja temática predominante em sua produção. Em $A$ morte do tenente e outras mortes (1979), por exemplo, o drama humano se alia às perambulações da escrita e, nesse percurso, o comerciante avarento cede lugar ao velho alquebrado imigrante que, no conto "O gramofone", rememora um episódio do seu passado, quando ainda era menino e vivia no Líbano, qual seja, a vinda e a permanência do tenente francês à pequena aldeia em que morava, como a marcar o início de um novo período de dominação após o fim do Império Turco-Otomano. Em um conto posterior, "Um bom negócio", esse mesmo personagem transformar-se-á no pai de familia que peregrina pelo interior de Santa Catarina tentando vender toneladas de camarão seco, iludido pela perspectiva de alcançar um misero lucro antes de retornar ao lar. Essa é a tragédia do modesto vendedor, o qual se encontra diante de um impasse, ocasionado, da mesma forma que no primeiro conto, por um agente externo: o recrudescimento da Guerra em nivel mundial e seus impactos político-econômicos. Os efeitos da crise são sentidos em todos os lugares, até mesmo naquela cidadezinha do interior catarinense, onde o personagem e a sua familia residem:

Um impasse. Com o recrudescer da guerra, o armazém ia de mal a pior tudo faltando, o dinheiro não circulava. Apertavam o cinto, economizavam nas menores coisas, a mulher se desfizera de umas joias de familia trazidas da terra, o marido suspendera a assinatura do jornal que lhe contava noticias do mundo, de sua pátria distante, daquele Libano que para ele era o de 1927 quando deixara sua terra e viajara para o Brasil com tantas esperanças, o filho mais velho fazia fretes, levava passageiros ao trote do velho cavalo [...], os mais moços ganhavam uns trocados escalando peixe na peixaria de "seu" Mendes, limpavam a chácara de "seu" Galiani em troca de frutas bichadas. Mas isto não chegava nem a ser paliativo. As dificuldades aumentavam, mesmo para quem possuía dinheiro, os gêneros, os alimentos sumiam (MIGUEL, 1979, p. 34). 
Assim, embora essas duas narrativas tratem de dois episódios distantes no tempo ( $1^{\mathrm{a}}$ e $2^{\mathrm{a}}$ guerras mundiais) e no espaço (Libano e Brasil), o personagem é o mesmo, assim como é idêntica a melodia que sai do gramofone do tenente, rememorada por Yussef, e aquela que repercute pelas ondas sonoras do rádio Phillips, no presente da enunciação. Nesse sentido, parece-nos que a primeira narrativa engloba essa segunda, seja pela reiteração do mesmo personagem e da mesma situação de crise política e econômica seja pela presença de fragmentos textuais que retomam a primeira história. Dessa forma, além de apontar para o modo como as relações assimétricas de poder estabelecem-se ao longo do globo (momentos de um mesmo "sistemamundo" moderno/colonial) ${ }^{8}$ e como elas afetam a vida de pessoas comuns, a narrativa encaixada reflete a narrativa encaixante no exato ponto em que "o passado realmente não passou" e, por essa razão, os fatos repetem-se no tempo como uma mesma cantilena a envolver a todos.

Esse mesmo personagem, Yussef-José Miguel, retornará em Nur na escuridão, revivendo o desconcertante e traumático desembarque no Brasil:

De novo o pai se cala. Olha para a rua, quer divisar carros que passam, a vista sempre mais fraca, nesta hora de lusco-fusco o movimento aumenta, ele se mexe remexe na cadeira, a janela é, ao mesmo tempo, seu mundo atual e seu passado. Quer se situar, [...] quer que a rua passe a representar o porto, o pasmo, o impasse, o movimento, os carros são navios, o pai acaba de chegar, não, não está ali naquele início de noite, na Av. Rio Branco, 84, Florianópolis, mas outra, outra vez é o anoitecer no cais da Praça Mauá, é sempre o 18 de maio, é o mesmo ano de 1927, é a nova maksuna à qual terão que ir se adaptando, terra que precisarão aprender a amar, é o embate entre duas concepções de mundo, de vida (MIGUEL, 2004, p. 17).

Acontecimento emblemático que marca o início de uma nova trajetória para o grupo familiar. Espécie de situação limitrofe para o imigrante, que representa a dualidade vivida pela família Miguel e remete à ideia de estar em um entre-lugar de negociação cultural e identitária, em um limiar entre o "lá", do país de origem, e o "cá", do país de destino.

Walter Benjamin (2006 apud GAGNENBIN, 2010) vai destacar que tais situações constituemse em ritos de passagem, em atos a partir dos quais se transpõem limiares não apenas espaciais como também temporais. Para o filósofo alemão, ao contrário da fronteira que delimita e contém, evitando que algo transborde para além dos limites do seu território; o limiar é uma zona, nem sempre claramente definida, que possui como função permitir a transição entre um espaço/tempo a outro. Inscrito nesse espaço/ tempo intermediário, o narrador de Nur, que se identifica com a personagem do filho mais velho de Yussef, vai transitar livremente entre o presente da enunciação e o passado rememorado; como também entre o "olhar de fora" e o "olhar de dentro", na tentativa de tecer o fio narrativo das memórias compartilhadas oralmente pelos pais com as suas próprias lembranças: "com pertinente monotonia, em busca de uma ilusória eficácia" (MIGUEL, 2004, p. 166).

Intenção bastante perceptivel na organização metódica da cena que inaugura o relato: com o dia, a hora, o ano, o local e as pessoas envolvidas no desembarque. Embora a aparente funcionalidade do esquema documental logo se desfaça ante o fluxo caótico da memória que estrutura o restante da narrativa:

E o fio outra vez rompido só volta a se unir (quantas vezes, em quantas diferentes ocasiões, em quais cidades também tão diferentes) tempos mais tarde. entrelaçando Biguaçu, Florianópolis, Rio de Janeiro, na mesma trama, na mesma teia, que acaba por envolver o país e a familia, cujo início acontecera no desconcertante e traumático desembarque (MIGUEL, 2004, p. 19).

Assim, o desembarque estabelece-se como ponto nodal a partir do qual o narrador

\footnotetext{
8 A expressão "sistema-mundo" moderno/colonial é utilizada a partir dos trabalhos teóricos de Walter Mignolo (2005). Para o autor, a colonialidade é constitutiva da modernidade, assim como o subdesenvolvimento é constitutivo do capitalismo, partes de um mesmo sistema-mundo que difunde instituições e formas de vida consideradas como civilizadas pelo globo, ao mesmo tempo em que utiliza um discurso fundado na racionalidade de suas práticas exploratórias e de dominação para justificá-las.
} 
entretece a trama das memórias familiares com a trama do país de destino, confrontando, por meio da recuperação de certas memórias marginalizadas e plurais, a ideia de uma história única e homogeneizadora em torno da qual se organiza a identidade nacional. Isso porque o questionamento de momentos importantes do passado da nação, como a Revolução de 1930, a instauração do Estado Novo, a Intentona Comunista, o Integralismo, o avanço das tropas nazistas na Europa, a participação do Brasil na 2. ${ }^{a}$ Guerra Mundial, dentre outros, surge em Nur de forma paralela à rotina familiar, que percebe e recebe seus reflexos. Sobre esse aspecto importa retomar o pensamento do escritor e antropólogo angolano, Ruy Duarte de Carvalho, sobre a volta paradigmática em si, ou seja, a capacidade de admitir e reconhecer que esse "outro", que possui uma visão distinta da realidade, seja capaz de perceber esses fenômenos históricos "de uma maneira melhor e mais adequada à efetiva configuração do mundo" (2011). Ou ainda, como afirma o filósofo latino-americano Enrique Dussel (2016), eles são capazes de responder com soluções completamente inovadoras aos impasses da modernidade, uma vez que partem de outro lugar, do ponto de vista de uma experiência cultural diferente, descentrada e/ ou ex-cêntrica, oposta à perspectiva dominante.

Nur inscreve-se, dessa maneira, conforme aponta a professora e pesquisadora Ana Maria Lisboa de Mello, dentro de uma "sensibilidade migratória", revelada na abertura da narrativa à alteridade, à cultura do Outro, como movimento fundamental para o conhecimento de si próprio. Nesse caso, a identidade dos personagens não se revela estática, mas em constante mutação, pois a herança cultural recebida dos pais articula-se e convive com aquela do país de destino e com os novos conhecimentos e desafios advindos desse processo. A narrativa de Salim Miguel, portanto, possuiria um "caráter transnacional, produzida por escritores cuja identidade incorpora à herança familiar as novas experiências culturais vividas no locus de acolhida" (MELLO, 2014, p. 172).

\section{Considerações finaîs}

Salim Miguel insere o personagem do imigrante libanês e de seus descendentes em um processo permanente de negociação cultural e identitária com os valores, os processos histórico-sociais e o modo de vida característico da nova maksuna brasileira. Nessa composição labiríntica, ele não apenas dialoga em suas narrativas com as formas de figuração do sujeito árabe ao longo da tradição literária brasileira, como também problematiza a própria ideia de uma memória única, homogeneizadora e sem fraturas em torno da qual se organiza a identidade nacional.

Durante esse percurso o escritor afasta-se de uma visão integradora de cultura tão cara ao debate multiculturalista: principalmente em relação à concepção de um país plural, no qual as fronteiras entre os grupos sociais, étnicos e raciais apagar-se-iam por conta da assimilação das diferenças. Da mesma forma, ao focar os embates e a resistência desse grupo étnico em integrarse totalmente à dinâmica cultural brasileira, mantendo alguns traços que o aproxima de sua comunidade étnica, o autor coloca em discussão o fato de que a cultura como lugar de encontro também é essencialmente um lugar de conflitos e disputas, pois o que marca os emigrados é o estranhamento do novo mundo.

\section{Referências}

ABDALA JUNIOR, Benjamin. Literatura comparada e relações comunitárias hoje. São Paulo: Ateliê Editorial, 2002.

AMADO, Jorge. A descoberta da América pelos turcos ou Os esponsais de Adma: romancinho. Rio de Janeiro: Record, 1994

CARVALHO, Ruy Duarte de. Tempo de ouvir o 'outro' enquanto o "outro" existe, antes que haja só o outro... Ou pré-manifesto neo-animista. In: Portal Buala. 2011. Disponivel em: https://www.buala.org/pt/ ruy-duarte-de-carvalho/tempo-de-ouvir-o-outro-enquanto-o-outro-existe-antes-que-haja-so-o-outro-ou-p. Acesso em: 12 abr. 2020.

CASTRO, Sílvio. A carta de Pero Vaz de Caminha. Porto Alegre: L\&PM, 2014

CORNEJO POLAR, Antonio. Sobre literatura y critica latinoamericanas. Caracas: Ediciones de la Facultad de Humanidades y Educación, Universidad Central de Venezuela, 1982 
DUSSEL, Enrique. Transmodernidade e interculturalidade: interpretação a partir da filosofia da libertação. Trad. Rodrigo de Freitas Espinoza. Revista Sociedade e Estado, v. 31, n.1, p. 51-73, jan./abr. 2016. https://doi. org/10.1590/S0102-69922016000100004

FREYRE, Gilberto. Casa-grande \& senzala: formação da familia brasileira sob o regime da economia patriarcal. Rio de Janeiro: Record, 1998.

GAGNEBIN, Jeanne Marie. Entre a vida e a morte. In: OTTE, G.; SEDLMAYER, S.; CORNELSEN, E. (org.). Limiares e passagens em Walter Benjamin. Belo Horizonte: Editora UFMG, 2010.

MIGNOLO, Walter. A colonialidade de cabo a rabo: o hemisfério ocidental no horizonte conceitual da modernidade. In: LANDER, Edgardo (org.). A colonialidade do saber: eurocentrismo e ciências sociais. Perspectivas latino-americanas. Colección Sur Sur. Buenos Aires: CLACSO, 2005.

MIGUEL, Salim. A morte do tenente e outras mortes. Rio de Janeiro: Edições Antares; Brasília: INL, 1979.

MIGUEL, Salim. Nur na escuridão. 4. ed. Rio de Janeiro: Top Books, 2004.

MIGUEL, Salim. Onze de Biguaçu, mais um. Florianópolis: Insular, 1997.

MIGUEL, Salim. Reinvenção da infância: romance. Osasco, SP: Novo Século Editora, 2011.

MIRANDA, Ana. Amrik. São Paulo: Companhia das Letras, 1997.

PAES, José Paulo. O lugar do outro: ensaios. Rio de Janeiro: TopBooks, 1999.

REIS, Carlos. Pessoas de Livro. Estudos sobre a Personagem. 2. ed. Coimbra: Imprensa da Univ. de Coimbra, 2016

SAID, Edward. Orientalismo: o Oriente como invenção do Ocidente. Trad. Rosaura Eichenberg. São Paulo: Companhia das Letras, 2007.

TRUZZI, Oswaldo. O lugar certo na época certa: sirios e libaneses no Brasil e nos Estados Unidos um enfoque comparativo. Estudos Históricos, Rio de Janeiro, n. 27, p.110-140, 2001

VILLAR, Valter Luciano. Os árabes e nós: a presença árabe na Literatura Brasileira. Tese. Universidade Federal da Paraíba. João Pessoa, 2012.

\section{Endereço para correspondência}

Ana Cláudia de Oliveira da Silva

Instituto Federal de Educação, Ciência e Tecnologia Farroupilha

Campus São Vicente do Sul

Rua 20 de Setembro, 2616, Prédio C, sala 8

97420-000

São Vicente do Sul, RS, Brasil 